\title{
Characterizing long-time scale hydrological effects on gravity for improved distinction of tectonic signals
}

\author{
M. Van Camp, ${ }^{1}$ L. Métivier, ${ }^{2,3}$ O. de Viron, ${ }^{3,4}$ B. Meurers, ${ }^{5}$ and S. D. P. Williams ${ }^{6}$ \\ Received 14 May 2009; revised 26 January 2010; accepted 16 February 2010; published 16 July 2010.
}

[1] The influence of the hydrological noise on repeated gravity measurements has been investigated on the basis of the time series of 18 superconducting gravimeters (SGs) and on predictions inferred from the Land Dynamics (LaD) world-Gascoyne land waterenergy balances model. Presently, the global hydrologic models are not precise enough to fulfill the geodetic requirements and are not efficient enough to separate the hydrology from tectonic motion in the land-based gravity time series. However, although the LaD model predictions and the gravity observations present significant differences in the time domain, it is shown that they have similar amplitudes in the frequency domain in most of the cases. The time series of the Global Geodynamics Project make it possible to investigate phenomena of a few years in the best case. Given the similarity between the power spectral densities (PSDs) of the LaD model predictions and the SG measurements when taken at the same epoch, it makes sense to use the $\mathrm{LaD}$ model to study the spectral behavior of the hydrological effects down to the decadal time scale, which is not yet possible with land-based measurements. It is shown that the PSDs of the hydrological effects flattens at low frequency and is characterized by a generalized Gauss-Markov structure. With such a noise level, the time necessary to measure a gravity rate of change of $1 \mathrm{~nm} / \mathrm{s}^{2} / \mathrm{a}$, at the $1 \sigma$ level should not extend any longer than 17 years at the locations where the hydrological effects play a major role.

Citation: Van Camp, M., L. Métivier, O. de Viron, B. Meurers, and S. D. P. Williams (2010), Characterizing long-time scale hydrological effects on gravity for improved distinction of tectonic signals, J. Geophys. Res., 115, B07407, doi:10.1029/2009JB006615.

\section{Introduction}

[2] To determine long-term vertical deformation, the use of absolute gravimeters is most appropriate, as no instrumental drift needs to be corrected. As with other geodetic quantities, gravity integrates many phenomena, and it remains a challenge to isolate the contribution from any particular source. Any change in the measured gravity can be caused by either mass change around the instrument, vertical displacement of the instrument itself, or both. In many areas, the hydrological signal dominates the measured gravimetric signal, after correcting for tidal, atmospheric, and polar motion effects [e.g., Van Camp et al., 2006; Longuevergne et al., 2009]. These hydrological effects can be more important

\footnotetext{
${ }^{1}$ Department of Seismology, Observatoire Royal de Belgique, Brussels, Belgium.

${ }^{2}$ Institut Géographique National, LAREG, Champs-sur-Marne, France.

${ }^{3}$ Institut de Physique du Globe de Paris, Paris, France.

${ }^{4}$ Université Paris Diderot Paris, Paris, France.

${ }^{5}$ Institut für Meteorologie und Geophysik, Universität Wien, Wien, Austria.

${ }^{6}$ Proudman Oceanographic Laboratory, Liverpool, United Kingdom.

Copyright 2010 by the American Geophysical Union.

0148-0227/10/2009JB006615
}

than any tectonic effects and may introduce large timecorrelated noise into the data, which may be described as a stochastic process.

[3] Accounting for the right type of noise is important not only when estimating gravity variations and their uncertainties but also when attempting to mitigate this noise. This study aims at examining the power spectrum of the gravity signal of hydrologic origin to determine how, and with what precision, we can separate the hydrology from tectonic motion in absolute gravimeter time series.

[4] Classically [Mandelbrot, 1983; Agnew, 1992], many geophysical signals can be described in terms of a power law in the frequency domain of the form

$$
P_{x}(f)=2 \sigma_{r w}^{2} \frac{(2 \pi f)^{\kappa}}{f_{s}^{\kappa+1}}
$$

where $f$ is the spatial or temporal frequency, $\sigma_{r w}$ is the scaling for the random walk part of the model, $f_{s}$ is the sampling frequency, and $\kappa$ is the spectral index [Mandelbrot and Van Ness, 1968]. The interpretation of the $\kappa$ value in terms of noise type is given in Table 1.

[5] However, not all geophysical signals follow a power law over all frequency ranges. Of particular interest to us is the first-order Gauss Markov (FOGM) process, with a random walk spectrum $(\kappa=-2)$ at high frequencies and a flat- 
Table 1. $\kappa$ Value in Term of Noise Type

\begin{tabular}{lc}
\hline$\kappa$ Value & Noise Type \\
\hline$[-3,-1]$ & Fractional Brownian motion \\
-2 & Random walk \\
-1 & Flicker (or pink) noise \\
0 & White noise \\
\hline
\end{tabular}

tening at low frequency; it is characterized by a power spectrum of the form

$$
P_{x}(f)=2 \sigma_{r w}^{2} \frac{f_{s}}{\beta^{2}+4 \pi^{2} f^{2}}
$$

where $\beta$ controls the crossover frequency (the frequency at which the spectrum flattens) and $\sigma_{r w}$ is the scaling for the random walk part of the model. This concept can be generalized to the Generalized Gauss Markov model (GGM), where the high-frequency power law can take any spectral index, $\kappa$, as opposed to just random walk. The power law then becomes

$$
P_{x}(f)=2 \sigma_{r w}^{2} \frac{\left(\beta^{2}+4 \pi^{2} f^{2}\right)^{\kappa / 2}}{f_{s}^{\kappa+1}}
$$

[6] It seems physically reasonable that the hydrological signal may obey some form of Gauss-Markov model, with the spectrum flattening at periods longer than a few years or more. For example, random walk behavior, because it is nonstationary, would theoretically allow the possibility that water may disappear globally over long periods of time or that unlimited amounts of water could be stored in the ground. Therefore, the separation of the hydrological and tectonic signals in the gravity can be achieved only by either one of the following methods: (1) The hydrological signal is known with a sufficient accuracy and can be corrected with precision better than the amplitude of the tectonic signal, or (2) it is assumed that the tectonic motion has a long-term trend, but not the hydrological signal. In other words, one can accumulate time series long enough to reach the lowfrequency part of the spectrum, where the frequency content of the hydrological signal would flatten out. This is investigated in this paper.

[7] Van Camp et al. [2005] studied the power spectra of several gravimetric series, recorded using absolute and superconducting gravimeters (SGs) at the Proudman Oceanographic Laboratory (Bidston, UK) and at the Membach station (eastern Belgium). They estimated, for a set of power noise models, the time necessary for a tectonic slope of $1 \mathrm{~nm} / \mathrm{s}^{2} /$ a (equivalent to a vertical displacement of $0.5 \mathrm{~mm} / \mathrm{a}$ ) to be separated from the climate signal. They showed that the data best fit a Fractional Brownian noise model, but physical considerations indicated that FOGM is more likely. Observed flattening of the power spectral densities (PSDs) at low frequency was observed, but such flattening has remained questionable. In this paper, based on actual time series from superconducting gravimeters and a hydrological model, we confirm that the observed flattening is a real effect.

[8] Numerous authors have studied the impact of environmental factors on the local gravity variations [e.g., Van Camp et al., 2006; Hokkanen et al., 2007; Naujoks et al.,
2008; Longuevergne et al., 2009; Lampitelli and Francis, 2010; Creutzfeld et al., 2010]. They showed, by studying the relationship between local gravity and water storage, that the hydrological effect dominates, after correcting the time series from well-known effects such as tides, polar motion, and atmospheric forcing. They also showed the importance of very local geologic and hydrologic conditions, e.g., the soil moisture, rock porosity, vegetation, and water tables. Based on in situ hydrogeological investigations, they built a model to account for the local hydrology effects in gravity time series. To generalize this type of study, one can use global hydrology models, which provide hydrology mass distribution as a function of time. However, these models are not sufficiently accurate to fully allow precise correction of gravity time series [Boy and Hinderer, 2006; Neumeyer et $a l ., 2006]$. On the other hand, only a few gravity stations are instrumented with adequately maintained soil moisture probes and piezometers. Therefore, the separation of hydrology and tectonic processes can be achieved only by accumulating data series that are long enough.

[9] This paper aims at determining the time required for the environmental signal to average out to a level sufficient for tectonic studies. At present, there is not enough available repeated absolute gravity time series to investigate the longterm behavior of gravity. On the other hand, SGs are continuously monitoring the gravity changes and time series are available through the Global Geodynamics Project (GGP [Crossley et al., 1999]) database. Apart from a linear or an exponential drift [Van Camp and Francis, 2006], the SGs provide the same information. Consequently, we used them to investigate the spectral signature of gravity measurements.

[10] In section 2, we present the data used and how they were preprocessed for our study. In section 3, the hydrological effects down to the decadal time scale are investigated using the predictions of the Land Dynamics (LaD) world-Gascoyne land water-energy balances model and comparing the spectral behavior of the SG time series and the LaD predictions. Finally, with a better understanding of the environmental noise affecting land-based gravity measurements, section 4 investigates the ability of land-based absolute gravity measurements to monitor slow gravity rates of change in different climatic regimes.

\section{Data Used and Their Preprocessing}

\subsection{Gravity data}

[11] In this study, we used 18 time series from the GGP database (see Table 2) [Crossley et al., 1999]. The time series have been corrected for tidal effects using tidal gravimetric factors obtained through the ETERNA package [Wenzel, 1996]; the atmospheric influence has been removed by applying a linear admittance of $-3.3 \mu \mathrm{Gal} / \mathrm{hPa}[$ Merriam, 1992]. The centrifugal effect associated with polar motion has also been corrected [Wahr, 1985]. Since our focus is on environmental effects, we also subtracted a degree 3 polynomial fit, accounting for any nonlinear instrumental drift and internal geophysical signal. A more sophisticated method, such as the one proposed by Van Camp and Francis [2006] to analyze the instrumental causes of the drift, requires numerous repeated absolute gravity measurements and is unnecessary in the scope of our study, as this does not modify the shape of the PSDs. 
Table 2. Global Geodynamics Project (GGP) Stations With Starting and Ending Times of the Time Series Used in This Study ${ }^{\mathrm{a}}$

\begin{tabular}{|c|c|c|c|c|c|c|}
\hline Station & Code & Latitude (Degrees) & Longitude (Degrees) & Starting Time & Ending Time & Length (in days) \\
\hline Bad Homburg & $\mathrm{BH}$ & 50.2285 & 8.6113 & 12 February 2001 & 4 April 2007 & 2242 \\
\hline Canberra & $\mathrm{CB}$ & -35.3206 & 149.0077 & 1 July 1997 & 18 April 2007 & 3578 \\
\hline Cantley & $\mathrm{CA}$ & 45.5850 & 284.1927 & 1 July 1997 & 31 January 2008 & 3866 \\
\hline Esashi & ES & 39.1511 & 141.3318 & 1 July 1997 & 25 Feb. 2004 & 2430 \\
\hline Kamioka & KA & 36.4253 & 137.3084 & 22 October 2004 & 25 Nov. 2005 & 399 \\
\hline Matsushiro & MA & 36.5439 & 138.2032 & 1 May 1997 & 30 June 2006 & 3347 \\
\hline Medicina & $\mathrm{MC}$ & 44.5219 & 11.6450 & 1 January 1998 & 31 August 2007 & 3529 \\
\hline Membach & MB & 50.6093 & 6.0066 & 4 August 1995 & 1 May 2008 & 4654 \\
\hline Metsähovi & $\mathrm{ME}$ & 60.2172 & 24.3958 & 1 July 1997 & 31 Dec. 2007 & 3835 \\
\hline Moxa & MO & 50.6447 & 11.6156 & 1 January 1999 & 29 Feb. 2008 & 2981 \\
\hline Ny Alesund & NA & 78.9306 & 11.8672 & 20 Sept. 1999 & 30 April 2007 & 2779 \\
\hline Strasbourg & ST & 48.6217 & 7.6850 & 1 March 1997 & 31 Dec. 2007 & 3957 \\
\hline Sutherland & SU & -32.3814 & 20.8109 & 27 March 2000 & 29 Feb. 2008 & 2895 \\
\hline Syowa & SY & -69.0067 & 39.5857 & 1 July 1997 & 31 January 2003 & 2040 \\
\hline Tigo-Concepcion & $\mathrm{TC}$ & -36.8437 & -73.0255 & 12 May 2002 & 29 Feb. 2008 & 2119 \\
\hline Vienna & VI & 48.2493 & 16.3579 & 1 July 1997 & 31 Dec. 2006 & 3470 \\
\hline Wettzell & WE & 49.1440 & 12.8780 & 13 June 1999 & 17 April 2007 & 2865 \\
\hline Wuhan & WU & 30.5159 & 114.4898 & 20 Dec. 1997 & 30 June 2007 & 2630 \\
\hline
\end{tabular}

${ }^{\mathrm{a}}$ Note that the Wuhan time series present an interruption of 845 days.

\subsection{The LaD Model}

[12] The LaD model [Milly and Shmakin, 2002; Shmakin et al., 2003] provides us with water storage data separated into subsurface water mass, surface (reservoir) water mass, and snow mass. Data are distributed as monthly $1^{\circ} \times 1^{\circ}$ grids, forced by estimated historical atmospheric conditions. The outputs of the LaD model were converted into gravity time variations by computing the sum of the gravity change resulting from the elastic deformation of the Earth due to the water mass load and the direct mass attraction [Farrell, 1972]. According to previous studies [Boy and Hinderer, 2006; Neumeyer et al., 2006], other global hydrology models (Global Land Data Assimilation System [Rodell et al., 2004] and the Leaky-Bucket Model H96 [Fan and van den Dool, 2004]) are no more successful in correcting gravity time series.

\section{Times Series and Power Spectral Densities}

\subsection{Time Series}

[13] Figure 1 shows the gravity time series at 18 GGP stations for the measured gravity (in black) and the LaDpredicted hydrologic effect, assuming that all the water and snow mass is situated below the instrument (in red). At some stations, however, particular configurations are such that part of the water mass should be considered above the instrument (see Table 3). The corresponding curves for such configurations are displayed in blue.

[14] As shown previously by Boy and Hinderer [2006] and Neumeyer et al. [2006], the observations differ strongly from the changes predicted using global hydrology models. Consequently (Table 4), correcting the measurements does not help and can even increase the variances of the time series. Some annual signals have the right amplitude, but they most often differ in phase. This poor agreement is due to the limited spatial coherence of the local scale hydrological noise. As shown, for example, by Creutzfeld et al. [2010], Hokkanen et al. [2007], Krause et al. [2009], Longuevergne et al. [2009], Naujoks et al. [2008], or Van Camp et al. [2006], most of the hydrological effects are induced by the water masses present in a radius $<1 \mathrm{~km}$ around the gravimeter. Therefore, it is currently unfeasible to extract the tectonic signal by correcting the SG series using global hydrology models.

\subsection{Power Spectral Densities}

[15] Instead of working in the temporal domain, another option consists of investigating the power law of the hydrological signal, and in particular if it does flatten at low frequency such that it averages out in the time series. This requires computing the power spectrum densities of the signals, which are displayed in Figures $2 \mathrm{a}$ and $2 \mathrm{~b}$. As the $\mathrm{LaD}$ simulation runs from 1980, we display both the PSD computed from the whole time series (red) and from the period overlapping with the SG observations (green).

[16] The generally higher level and slope of the PSDs of the SGs at low frequency is probably due to local hydrological effects and, to a lesser extent and depending on the station, to instrumental artifacts. Let us discuss different cases.

\subsubsection{The PSD of the SGs Higher Than the LaD Model} (Same Epoch)

[17] 1. For Membach, one has access to collocated repeated absolute measurements, which are quite useful to control the correction of severe jumps, which have affected the SG data. Those jumps are mainly due to power outages and helium fillings, and if improperly corrected, they may increase the PSD level. However, the SG at Membach presents a slope close to -2 in spite of the accurate control made using the absolute gravimeter. On the other hand, it is known that the gravity signal can decrease by a few dozen $\mathrm{nm} / \mathrm{s}^{2}$ within a few minutes during rainfall [Francis et al., 2004; Van Camp et al., 2006; Meurers et al., 2007]. These steplike hydrological signals contribute to increase the slope of the PSD, as the spectral index of the PSD of a Heaviside function is -2 [Williams, 2003a].

[18] It is also worth noting that after applying the local hydrological model of Van Camp et al. [2006], the PSD is lower at low frequency as shown in Figure 3. This indicates that the hydrological effects play an important role on the structure of the PSD at the Membach station. Hydrological models are being developed at other stations, but unfortunately their influences on the PSDs are unpublished. 

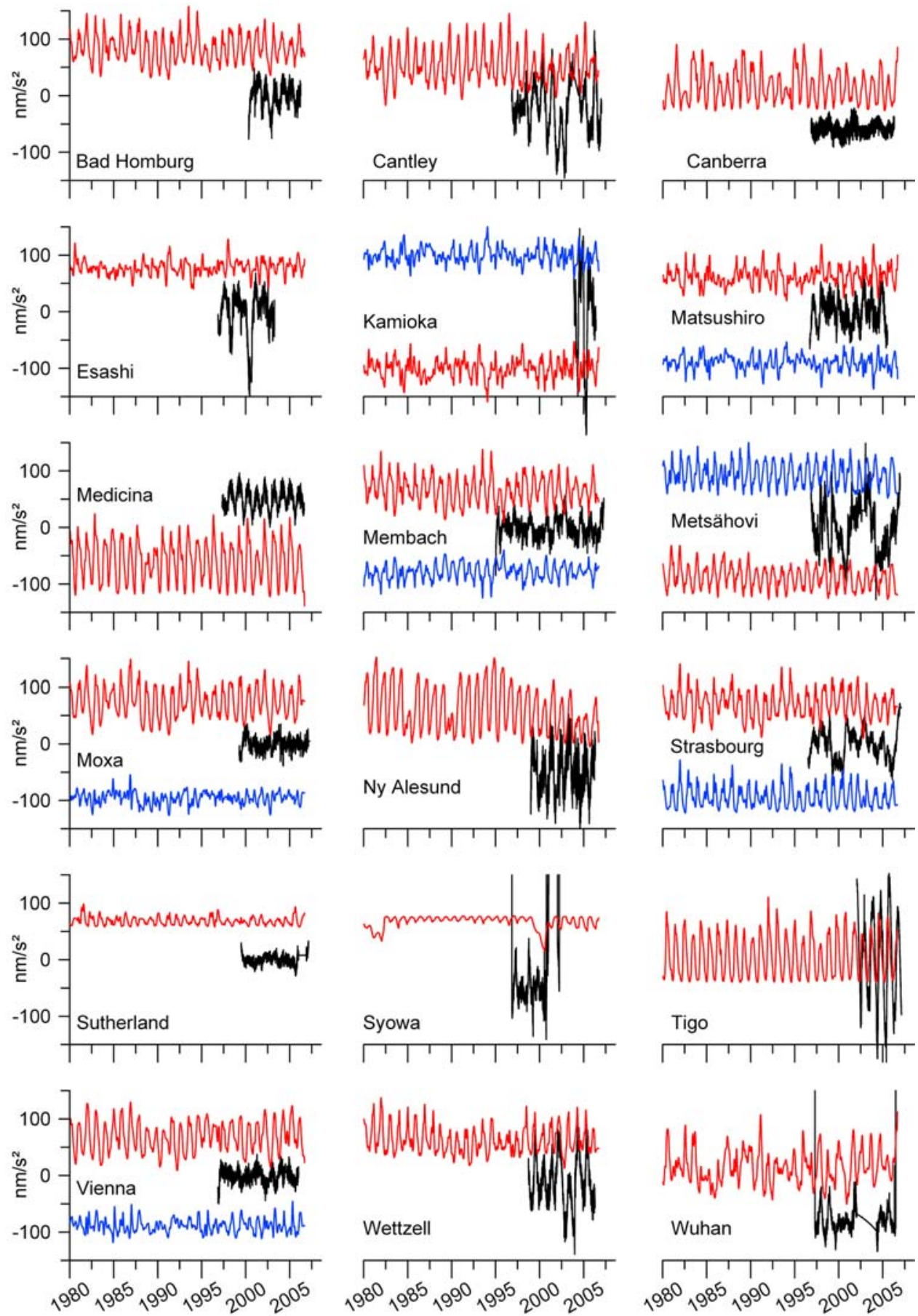

Figure 1. The superconducting gravimeters (SG) time series (in black) and the gravity data predicted by the Land Dynamics ( $\mathrm{LaD}$ ) world-Gascoyne land water-energy balances model (in red and blue). The red curve is computed assuming all the mass below the instrument, whereas the blue curves account for the particular geometry (see Table 3).

[19] 2. At Matsushiro, a similar fast drop has been observed in response to rainfall [Imanishi et al., 2004, 2006]. This is similar to Membach; those fast changes influence the whole frequency band and could not be modeled by the LaD model, given the 1-month sampling rate and the space resolution. Such behavior, mainly caused by soil moisture changes, has also been reported at the underground gravity stations of Walferdange, Luxembourg
[Lampitelli and Francis, 2010], and Bandung, Indonesia [Abe et al., 2006].

[20] 3. At Cantley, fast rises have been reported, and as shown in Figure 1, strong irregular seasonal variations are also observed due to changes in the nearby water table and snow melt [Bower and Courtier, 1998].

[21] 4. At Tigo, strong annual and interannual signals can be observed on both the $\mathrm{SG}$ and $\mathrm{LaD}$ time series (Figure 1). 
Table 3. Stations Where Part of the Water Mass is Above the Gravimeter

\begin{tabular}{lll}
\hline \multicolumn{1}{c}{ Station } & \multicolumn{1}{c}{ Water Mass Position } & \multicolumn{1}{c}{ Reference } \\
\hline Kamioka & All the mass above & Takemoto et al. [2006] \\
Matsushiro & All the mass above & Imanishi et al. $[2004$, 2006] \\
Membach & All the mass above & Van Camp et al. [2006] \\
Metsähovi & Snow above & Virtanen [2000] \\
Moxa & Soil moisture and snow above & Naujoks et al. [2008] \\
Strasbourg & Soil moisture and snow above & Longuevergne et al. [2009] \\
Vienna & Soil moisture and snow above & Meurers et al. [2007] \\
\hline
\end{tabular}

However, the amplitude is stronger in the SG data due to local hydrogeological effects. The station is located $2 \mathrm{~km}$ away from the Biobio river [Wilmes et al., 2005], the influence of which cannot be predicted by the $1^{\circ} \times 1^{\circ} \mathrm{LaD}$ model.

[22] 5. At Metsähovi, Strasbourg, and Wettzell, the studies of Hokkanen et al. [2007], Longuevergne et al. [2009], and Creutzfeldt et al. [2010] also confirm the influence of local hydrology and especially soil moisture on the SG time series. This was also suspected by Sato et al. [2006] at Ny Alesund.

[23] 6. Syowa and Kamioka are the only stations where the PSDs of SG data and $\mathrm{LaD}$ model show a significant disagreement. These are not too much of a concern: the SG time series of Kamioka is too short to reach a meaningful conclusion, and the Syowa station is located in a polar region, where the $\mathrm{LaD}$ model is unreliable (P. C. D. Milly, personal communication).

[24] 7. As far as we know, no information is available on the local hydrological effects at the Esashi station.

3.2.2. The PSD of the SGs Lower Than or Similar to the LaD Model (Same Epoch)

[25] 1. At Medicina station, the gravity signal is highly correlated with the nearby water table, located a few meters underneath the gravimeter [Zerbini et al., 2001]. These variations and their effects on gravity are smooth and mostly seasonal, which explains why Medicina presents one of the flattest PSDs at low frequency and therefore one of the shortest times $T_{1}$ necessary to measure a slope with an uncertainty of $1 \mathrm{~nm} / \mathrm{s}^{2} / \mathrm{a}$ (Table 5 ).
[26] 2. Vienna station is located on a gentle topographic slope, and the surface close to the station is well above the SG. However, this does not hold for the distant terrain. Therefore, the gravity effect of mass distributed above and below the station partly compensates [Meurers et al., 2007]. The case of Moxa is similar [Naujoks et al., 2008; Krause et al., 2009]. This can explain why these stations belong to those with the lowest $T_{1}$.

[27] 3. In Bad Homburg, Harnisch et al. [2006] do not discuss the role of the soil moisture, but they discuss the influence of the castle housing and waterproofing the SG, as well as the presence of a confined aquifer, which should not influence the gravity. This may explain the relatively low level of the PSD of the SG.

[28] 4. Sutherland has a low rainfall average of $169 \mathrm{~mm} /$ year, with most of these weak precipitations occurring during wintertime. This explains the low level of the PSDs and their low slope.

[29] 5. For Canberra and Wuhan, the LaD predictions are at a much higher level than the SG observations. This may be due to the fact that the SGs are on the bedrock, at the tops of mountains (Mount Stromlo, west of Canberra [http://ilrs. gsfc.nasa.gov/stations/sitelist/STL3_sitelog.html]; and Yanjia Mountain, suburb of Wuhan [Xu et al., 2008]), where the drainage is probably quite efficient.

[30] Although the slopes present differences, the agreement between the PSD levels of the SG and LaD time series indicates that at periods longer than a couple of months, the gravity time series are dominated by hydrological effects. The poor agreement in the time domain is due to the limited spatial coherence of the local scale hydrological noise. However, at interannual periods, the coherence should increase and common regional behavior should be found in the future.

\section{How Long Is Long Enough?}

[31] With the SG data, we estimate the spectral index $\kappa$ by a maximum likelihood estimation (MLE) by fitting the power law (equation 1) and the stochastic GGM (equation 3) models to the time series [Williams, 2003b; Langbein, 2004]

Table 4. Standard Deviation of the SG Time Series Before and After Applying the LaD Model ${ }^{\mathrm{a}}$

\begin{tabular}{|c|c|c|c|c|}
\hline Station & Raw Data $\left[\mathrm{nm} / \mathrm{s}^{2}\right]$ & Model Variance $\left[\mathrm{nm} / \mathrm{s}^{2}\right]$ & Alternative Model Variance $\left[\mathrm{nm} / \mathrm{s}^{2}\right]$ & Change in Variance $[\%]$ \\
\hline Bad Homburg & 20.6 & 25.3 & N/A & 23 \\
\hline Canberra & 9.1 & 24.0 & $\mathrm{~N} / \mathrm{A}$ & 164 \\
\hline Cantley & 45.1 & 42.4 & N/A & -6 \\
\hline Esashi & 39.2 & 38.8 & $\mathrm{~N} / \mathrm{A}$ & -1 \\
\hline Kamioka & 82.3 & 79.4 (SG below masses) & 88.3 (SG above) & $-4 / 7$ \\
\hline Matsushiro & 24.0 & 29.0 (SG below masses) & 26.7 (SG above) & $21 / 11$ \\
\hline Medicina & 17.5 & 25.0 & N/A & 43 \\
\hline Membach & 16.9 & 16.6 (SG below masses) & 32.8 (SG above) & $-2 / 94$ \\
\hline Metsähovi & 40.7 & 42.0 & 42.9 (snow above) & $3 / 5$ \\
\hline Moxa & 11.0 & 13.4 (Snow, soil moisture above) & 31.1 (SG above) & $22 / 183$ \\
\hline Ny Alesund & 34.3 & 32.2 & $\mathrm{~N} / \mathrm{A}$ & -6 \\
\hline Strasbourg & 26.0 & 38.8 & 34.5 (snow, soil moisture above) & $49 / 33$ \\
\hline Sutherland & 7.4 & 11.7 & N/A & 58 \\
\hline Syowa & 86.7 & 86.3 & N/A & $\mathbf{0}$ \\
\hline Tigo & 78.7 & 72.3 & N/A & -8 \\
\hline Vienna & 12.1 & 30.2 & 18.6 (snow, soil moisture above) & $150 / 54$ \\
\hline Wettzell & 43.5 & 36.7 & $\mathrm{~N} / \mathrm{A}$ & -16 \\
\hline Wuhan & 18.1 & 30.1 & N/A & 66 \\
\hline
\end{tabular}

${ }^{a}$ Also shown is the relative difference (in $\%$, boldfaced when the variance is diminished). 

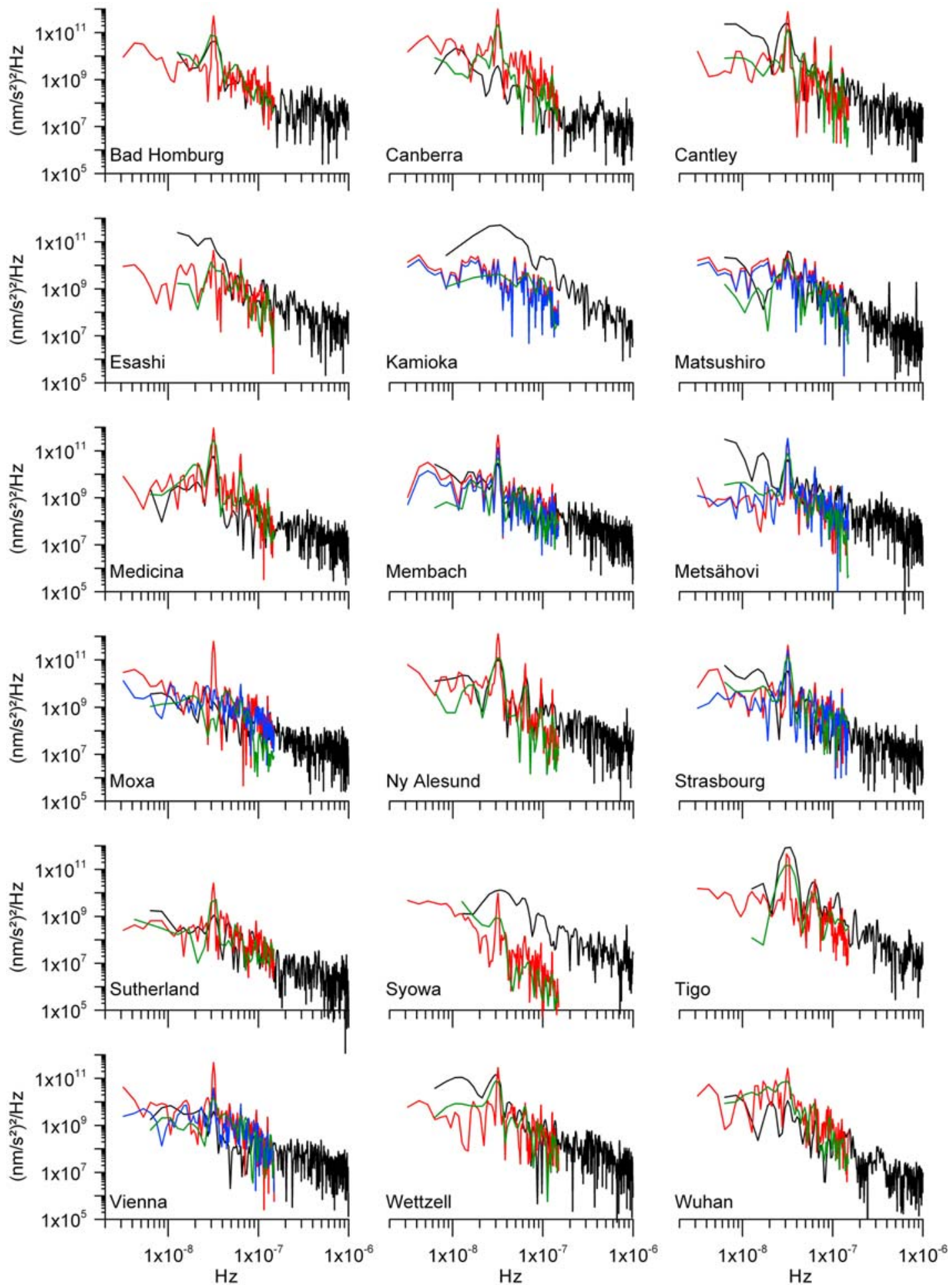

Figure 2. (a) Power spectrum densities (PSDs) of the observed gravity variations (black) and the LaD inferred gravity variations (red, blue, green). The red curve is computed assuming all the mass below the instrument, whereas the blue curves account for the particular geometry (see Table 3 ). The green curves are similar to the blue (when applicable) or red ones but were computed at the same epoch as the SG time series. (b) Same as (a), zoom on the seasonal part of the spectrum.

using the fast MLE algorithm described in Bos et al. [2008]. The results of the fit are shown in Table 5, which provides the spectral index $\kappa$ and the Bayesian Information Criterion (BIC) [Schwarz, 1978]. For the GGM model, it also pro- vides the scaling for the random walk part of the model $\sigma_{r w}$ and the time $T_{1}$ necessary to measure a slope with an uncertainty of $1 \mathrm{~nm} / \mathrm{s}^{2} / \mathrm{a}$. This corresponds to a vertical deformation of $0.5 \mathrm{~mm} / \mathrm{yr}$. This time exceeds 10 years at 

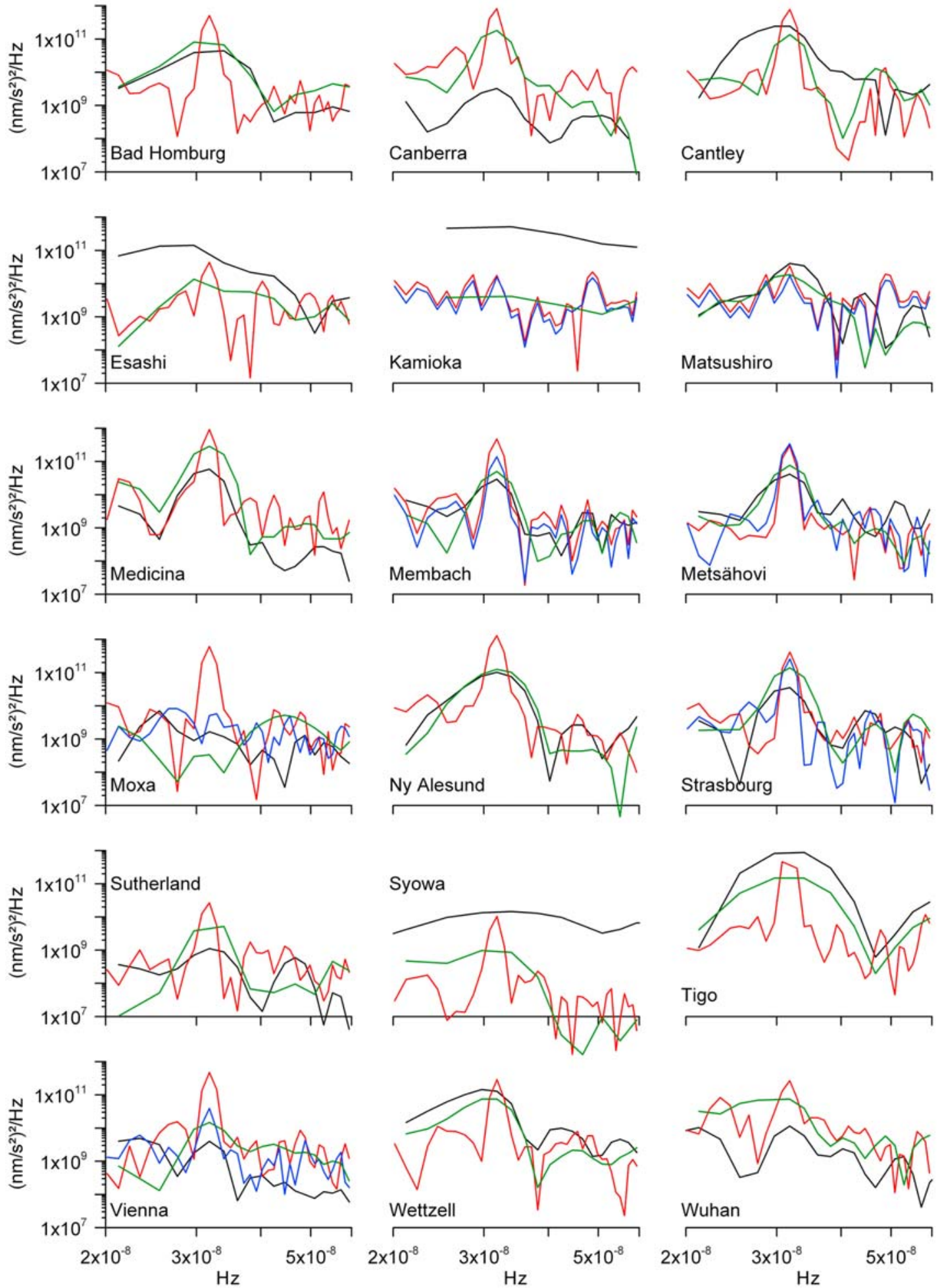

Figure 2. (continued)

Cantley, Esashi, Kamioka, Metsähovi, Ny Alesund, Strasbourg, Tigo, and Wettzell because of the strong seasonal or interannual variations.

[32] The model with the lowest BIC is preferred; this is the case of the GGM model everywhere except at Canberra,
Esashi, Kamioka, and Sutherland stations. As mentioned before, the Kamioka time series is much too short to afford any conclusions, and the Esashi BICs are actually equal. The Canberra and Sutherland cases may be due paradoxically to the low hydrological noise. In other words, its effect 


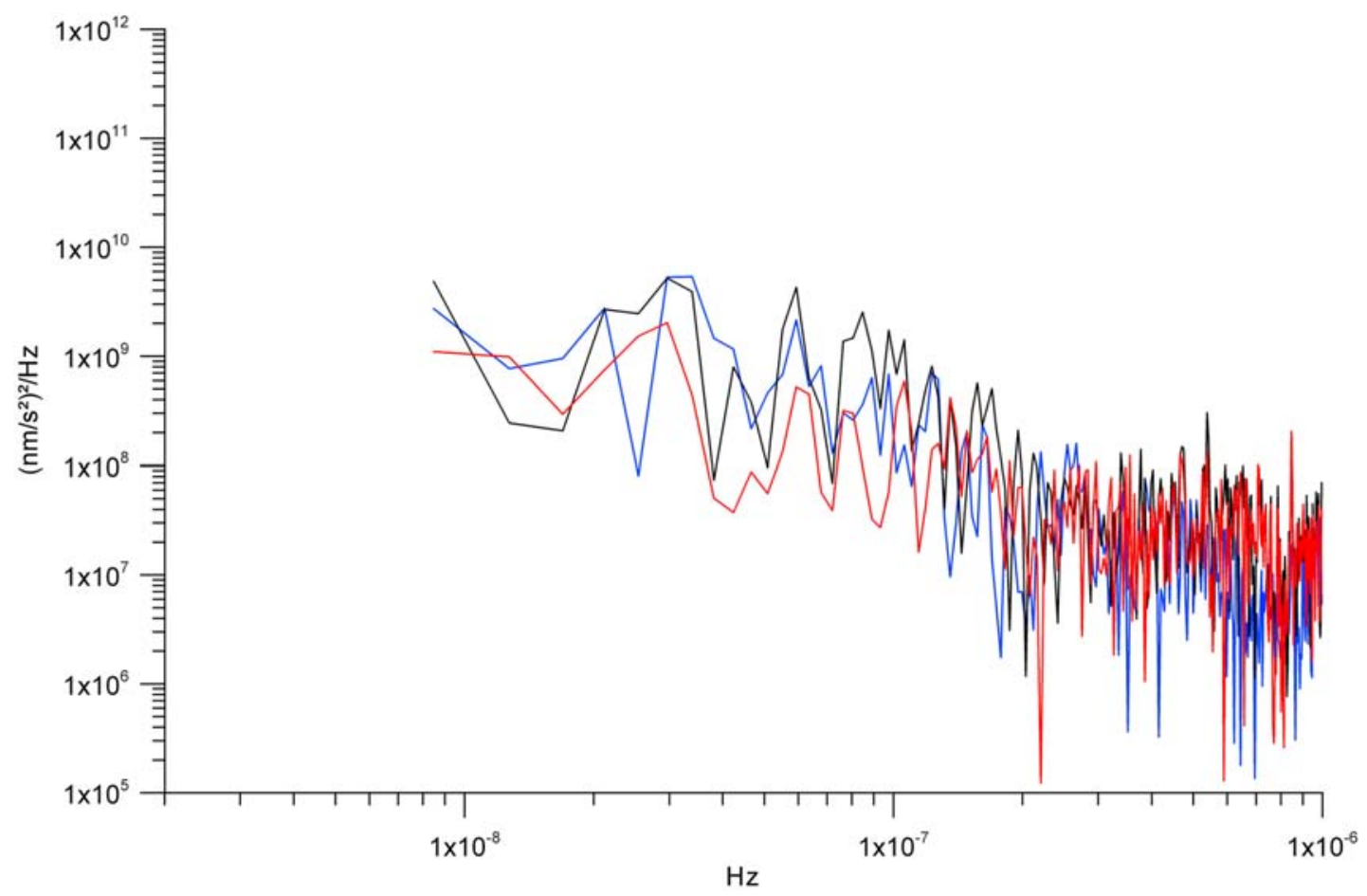

Figure 3. Power spectrum densities for the Membach station before (black) and after (red) applying the local hydrological correction of Van Camp et al. [2006]. The PSD of the hydrological model is also shown (blue).

is too weak to allow us to observe a significant flattening (according to the BIC applied here). It is also worth noting that (1) considering a power law noise, the spectral indexes are among the lowest at these two stations and (2) the PSD in Canberra is at a lower level for the SG than for the LaD. Therefore, even in those four cases, the time $T_{l}$ was computed assuming the GGM law.

[33] This approach could not be applied to the LaD model, owing to the insufficient time sampling of monthly data, which is too sparse and provides meaningless results. However, because of the local hydrological effects discussed in the previous section and possible instrumental artifacts, the results given in Table 5 are probably more conservative and realistic estimates than the $\mathrm{LaD}$ would provide.

[34] For most stations, the time series are not long enough to study periods longer than $\sim 5$ years. To investigate the lowest frequencies, we can extrapolate the power law using the $\mathrm{LaD}$ data, considering the similarity between the PSDs

Table 5. Results of the Analysis of the SG Time Series: Spectral Index $\kappa$, Scaling Factor $\sigma_{r w}$, Length $T_{1}$ (in Years) of the Data Set Needed to Separate a Tectonic Trend of $1 \mathrm{~nm} / \mathrm{s}^{2} / \mathrm{a}$ from Hydrological Signal at the $1 \sigma$ Level $^{\mathrm{a}}$

\begin{tabular}{|c|c|c|c|c|c|c|}
\hline \multirow[b]{2}{*}{ Station } & \multicolumn{4}{|c|}{ Generalized Gauss Markov } & \multicolumn{2}{|c|}{ Power Law Only } \\
\hline & $\kappa$ & $\mathrm{BIC}$ & $\sigma_{r w}\left[\mathrm{~nm} / \mathrm{s}^{2}\right]$ & $T_{I}[\mathrm{a}]$ & $\kappa$ & $\mathrm{BIC}$ \\
\hline Bad Homburg & $-2.69 \pm 0.15$ & 10338 & $4.83 \pm 0.08$ & $7.8 \pm 3.9$ & -2.3 & 10357 \\
\hline Canberra & $-1.39 \pm 0.04$ & 13342 & $2.76 \pm 0.04$ & $5.2 \pm 1.4$ & -1.4 & 13335 \\
\hline Cantley & $-2.09 \pm 0.04$ & 17806 & $4.97 \pm 0.07$ & $14.8 \pm 2.8$ & -2.0 & 17911 \\
\hline Esashi & $-1.96 \pm 0.05$ & 11529 & $5.30 \pm 0.09$ & $16.5 \pm 11.5$ & -1.9 & 11255 \\
\hline Kamioka & $-2.28 \pm 0.08$ & 5154 & $7.54 \pm 0.20$ & $15.2 \pm 4.3$ & -2.2 & 5154 \\
\hline Matsushiro & $-2.22 \pm 0.06$ & 14657 & $4.24 \pm 0.06$ & $6.8 \pm 0.5$ & -2.0 & 14694 \\
\hline Medicina & $-3.75 \pm 0.29$ & 14979 & $3.89 \pm 0.05$ & $3.1 \pm 0.1$ & -1.9 & 15150 \\
\hline Membach & $-2.49 \pm 0.07$ & 19373 & $3.82 \pm 0.05$ & $5.5 \pm 0.3$ & -2.1 & 19479 \\
\hline Metsähovi & $-2.42 \pm 0.06$ & 19133 & $6.41 \pm 0.08$ & $12.7 \pm 1.2$ & -2.2 & 19168 \\
\hline Moxa & $-2.84 \pm 0.14$ & 12707 & $3.69 \pm 0.05$ & $3.6 \pm 0.2$ & -2.0 & 12829 \\
\hline Ny Alesund & $-1.59 \pm 0.05$ & 15194 & $8.67 \pm 0.13$ & $9.8 \pm 3.1$ & -1.5 & 15196 \\
\hline Strasbourg & $-2.14 \pm 0.05$ & 15499 & $3.02 \pm 0.04$ & $11.8 \pm 5.1$ & -2.1 & 15500 \\
\hline Sutherland & $-1.48 \pm 0.04$ & 10010 & $2.28 \pm 0.03$ & $5.6 \pm 2.2$ & -1.5 & 10001 \\
\hline Syowa & $-2.55 \pm 0.13$ & 6246 & $4.65 \pm 0.10$ & $8.4 \pm 7.6$ & -2.3 & 6256 \\
\hline Tigo & $-2.38 \pm 0.05$ & 8490 & $4.25 \pm 0.08$ & $16.7 \pm 8.1$ & -2.3 & 8492 \\
\hline Vienna & $-4.66 \pm 0.39$ & 14561 & $3.96 \pm 0.06$ & $3.2 \pm 0.1$ & -2.0 & 14805 \\
\hline Wettzell & $-2.63 \pm 0.08$ & 13199 & $4.90 \pm 0.07$ & $10.1 \pm 0.9$ & -2.4 & 13240 \\
\hline Wuhan & $-2.35 \pm 0.06$ & 13989 & $3.35 \pm 0.05$ & $5.6 \pm 0.4$ & -2.1 & 14046 \\
\hline
\end{tabular}

${ }^{a}$ The Bayesian Information Criterion (BIC) is also provided for the Generalized Gauss Markov versus the power law noise structures, as well as the slope in the case of the power noise hypothesis. Boldface is used for the model with the lower value of BIC. 
for the overlapping epochs; this allows us to reach periods close to 15 years. In all cases (except for the Syowa station), the power spectra of the LaD model flatten, which substantiates our results favoring a Gauss Markov structure in the hydrological signal. In the future, slow climate changes may affect the gravity measurements, but this should be observed at the continental scale and a common mode should appear in the different time series, as well as in the hydrological models.

\section{Conclusions}

[35] The influence of the hydrological noise on repeated gravity measurements has been investigated based on 18 continuous SG time series and on predictions of the $\mathrm{LaD}$ model. Local hydrological effects and possible instrumental artifacts limit the flattening of the PSDs of the SG at low frequency, but the PSDs of the SGs and of the LaD predictions present similar amplitudes. Applying the BIC to the analysis of the SG time series, the generalized Gauss Markov structure is favored, which confirms the hypothesis of Van Camp et al. [2005].

[36] Given that the SG time series are all shorter than a dozen years, and considering the similar spectral behavior of the LaD model (which produced a run length of $>35$ years); the $\mathrm{LaD}$ model was used to confirm the flattening of the PSDs of the hydrological effects on gravity at long periods.

[37] Consequently, we can estimate the length of the data set needed to separate a tectonic trend of $1 \mathrm{~nm} / \mathrm{s}^{2} / \mathrm{a}$ from hydrological signal at the $1 \sigma$ level. It ranges from 3.5 years to 17 years, depending on the magnitude of the hydrological signal.

[38] Acknowledgments. We are grateful to L. Vandercoilden for processing the Global Geodynamics Project (GGP) time series, to C. Milly and A.B. Shmakin for making available the Land Dynamics worldGascoyne land water-energy balances model, as well as to all the GGP participants for making available the superconducting gravimeter data Discussions with and insights from T. Camelbeeck were also useful and much appreciated. The work benefited from valuable reviews by Y. Imanish and an anonymous associate editor. The work of O.V. and L.M. is IPGP contribution number 3031 .

\section{References}

Abe, M., S. Takemoto, Y. Fukuda, T. Higashi, Y. Imanishi, S. Iwano, S Ogasawara, Y. Kobayashi, A. Dwipa, and D. S. Kusuma (2006), Hydrological effects on the superconducting gravimeter observation in Bandung, J. Geodyn., 41(1-3), 288-295, doi:10.1016/j.jog.2005.08.030.

Agnew, D. C. (1992), The time-domain behaviour of power-law noises, Geophys. Res. Lett., 19(4), 333-336, doi:10.1029/91GL02832.

Bos, M. S., R. M. S. Fernandes, S. D. P. Williams, and L. Bastos (2008), Fast error analysis of continuous GPS observations, J. Geod., 82(3), 157-166, doi:10.1007/s00190-007-0165-x.

Bower, D. R., and N. Courtier (1998), Precipitation effects on gravity measurements at the Canadian Absolute Gravity Site, Phys. Earth Planet. Inter., 106(3-4), 353-369, doi:10.1016/S0031-9201(97)00101-5.

Boy, J.-P., and J. Hinderer (2006), Study of the seasonal gravity signal in superconducting gravimeter data, J. Geodyn., 41, 227-233, doi:10.1016/ j.jog.2005.08.035.

Creutzfeldt, B., A. Güntner, H. Thoss, B. Merz, and H. Wziontek (2010), Measuring the effect of local water storage changes on in-situ gravity observations: Case study of the Geodetic Observatory Wettzell, Germany, Water Resour. Res., doi:10.1029/2009WR008359, in press.

Crossley, D., et al. (1999), Network of superconducting gravimeters benefits several disciplines, Eos Trans. $A G U, 80(11), 121-126$, doi:10.1029/ 99EO00079.
Fan, Y., and H. van den Dool (2004), The CPC global monthly soil moisture data set at 1/2 degree resolution for 1948-present, J. Geophys. Res., 109 , D10102, doi:10.1029/2003JD004345

Farrell, W. E. (1972), Deformation of the Earth by surface loads, Rev. Geophys. Space Phys., 10, 761-797, doi:10.1029/RG010i003p00761.

Francis, O., M. Van Camp, T. van Dam, R. Warnant, and M. Hendrickx (2004), Indication of the uplift of the Ardenne in long term gravity variations in Membach (Belgium), Geophys. J. Int., 158, 346-352, doi:10.1111/j.1365-246X.2004.02310.x.

Harnisch, G., M. Harnisch, and R. Falk (2006), Hydrological influences on the gravity variations recorded at bad Homburg, Bull. Inf, Marées Terrestres, $124,11,331-11,342$.

Hokkanen, T., H. Virtanen, and M. Pirttivaara (2007), On hydrogeological noise in superconducting gravimeter data, Near Surface Geophys., 5(2), $125-131$.

Imanishi, Y., T. Sato, T. Higashi, W. Sun, and S. Okubo (2004), A network of superconducting gravimeters detects submicrogal coseismic gravity changes, Science, 306, 476-478, doi:10.1126/science.1101875.

Imanishi, Y., K. Kokubo, and H. Tatehata (2006), Effect of underground water on gravity observation at Matsushiro, Japan, J. Geodyn., 41(1-3), 221-226, doi:10.1016/j.jog.2005.08.031

Krause, P., M. Naujoks, M. Fink, and C. Kroner (2009), The impact of soil moisture changes on gravity residuals obtained with a superconducting gravimeter, J. Hydrol. Amsterdam, 373, 151-163, doi:10.1016/j.jhydrol.2009.04.019.

Lampitelli, C., and O. Francis (2010), Hydrological effects on gravity and correlations between gravitational variations and level of the Alzette River at the station Walferdange, Luxembourg, J. Geodyn., 49, 31-38, doi:10.1016/j.jog.2009.08.003.

Langbein, J. (2004), Noise in two-color electronic distance meter measurements revisited, J. Geophys. Res., 109, B04406, doi:10.1029/ 2003JB002819.

Longuevergne, L., J.-P. Boy, N. Florsch, D. Viville, G. Ferhat, P. Ulrich, B. Luck, and J. Hinderer (2009), Local and global hydrological contributions to gravity variations observed in Strasbourg, J. Geodyn., 48, 189194, doi:10.1016/j.jog.2009.09.008.

Mandelbrot, B. (1983), The Fractal Geometry of Nature, 466 pp., W. H Freeman, New York.

Mandelbrot, B., and J. Van Ness (1968), Fractional Brownian motions, fractional noises and applications, SIAM Rev., 10, 422-439, doi: $10.1137 / 1010093$

Merriam, J. B. (1992), Atmospheric pressure and gravity, Geophys. J. Int., 109, 488-500, doi:10.1111/j.1365-246X.1992.tb00112.x.

Meurers, B., M. Van Camp, and T. Petermans (2007), Correcting superconducting gravity time-series using rainfall modeling at the Vienna and Membach stations and application to Earth tide analysis, J. Geod., 81 (11), doi:10.1007/s00190-007-0137-1.

Milly, P. C. D., and A. B. Shmakin (2002), Global modeling of land water and energy balances. Part I. The land dynamics (LaD) model, J. Hydromet., 3, 283-299 ftp://ftp.gfdl.noaa.gov/pub/pcm/ladworld/gascoyne, doi:10.1175/1525-7541(2002)003<0283:GMOLWA >2.0.CO;2.

Naujoks, M., A. Weise, C. Kroner, and T. Jahr (2008), Detection of small hydrological variations in gravity by repeated observations with relative gravimeters, J. Geod., 82(9), doi:10.1007/s00190-007-0202-9.

Neumeyer, J., et al. (2006), Combination of temporal gravity variations resulting from superconducting gravimeter $(\mathrm{SG})$ recordings, GRACE satellite observations and global hydrology models, J. Geod., 79(10-11), 573-585, doi:10.1007/s00190-005-0014-8.

Rodell, M., et al. (2004), The global land data assimilation system, Bull. Am. Meteorol. Soc., 85, 381-394, doi:10.1175/BAMS-85-3-381.

Sato, T., J.-P. Boy, Y. Tamura, K. Matsumoto, K. Asari, H.-P. Plag, and O. Francis (2006), Gravity tide and seasonal gravity variation at Ny-Alesund, Svalbard in Arctic, J. Geodyn., 41(1-3), 234-241, doi:10.1016/j. jog.2005.08.016.

Schwarz, G. E. (1978), Estimating the dimension of a model, Ann. Stat., 6(2), 461-464, doi:10.1214/aos/1176344136.

Shmakin, A. B., P. C. D. Milly, and K. A. Dunne (2003), Global modeling of land water and energy balances. Part III: Interannual variability, J. Hydrometeorol., 3(3), 311-321, doi:10.1175/1525-7541(2002) $003<0311$ :GMOLWA $>2.0 . \mathrm{CO} ; 2$.

Takemoto, S., et al. (2006), A $100 \mathrm{~m}$ laser strainmeter system in the Kamioka mine, Japan, for precise observations of tidal strains, J. Geodyn., 41, 2329, doi:10.1016/j.jog.2005.08.009.

Van Camp, M., and O. Francis (2006), Is the instrumental drift of superconducting gravimeters a linear or exponential function of time? J. Geod., doi:10.1007/s00190-006-0110-4.

Van Camp, M., S. D. P. Williams, and O. Francis (2005), Uncertainty of absolute gravity measurements, J. Geophys. Res., 110, B05406, doi:10.1029/2004JB003497. 
Van Camp, M., M. Vanclooster, O. Crommen, T. Petermans, K. Verbeeck, B. Meurers, T. van Dam, and A. Dassargues (2006), Hydrogeological investigations at the Membach station, Belgium and application to correct long periodic gravity variations, J. Geophys. Res., 111, B10403, doi:10.1029/2006JB004405.

Virtanen, H. (2000), On the observed hydrological environmental effects on gravity at the Metsähovi station, Finland, in Cah. Cent. Eur. Géodyn. Séismol, vol. 17, edited by B. Ducarme and J. Barthélemy, pp. 169-175, Cent. Eur. de Géodyn. et de Séismol, Luxembourg.

Wahr, J. (1985), Deformation induced by polar motion, J. Geophys. Res., 90(B11), 9363-9368, doi:10.1029/JB090iB11p09363.

Wenzel, H.-G. (1996), The nanogal software: Earth tide data processing package, ETERNA 3.30, Bull. Inf, Marées Terrestres, 124, 9425-9439.

Williams, S. D. P. (2003a), Offsets in Global Positioning System time series, J. Geophys. Res., 108(B6), 2310, doi:10.1029/2002JB002156.

Williams, S. D. P. (2003b), The effect of coloured noise on the uncertainties of rates estimated from geodetic time series, J. Geod., 76, 483-494 doi:10.1007/s00190-002-0283-4.

Wilmes, H., A. Boer, B. Richter, M. Harnisch, G. Harnisch, H. Hase, and G. Engelhard (2005), A new data series observed with the remote superconducting gravimeter GWR R038 at the geodetic fundamental station TIGO in Concepcion (Chile), J. Geodyn., 41, 5-13, doi:10.1016/j. jog.2005.08.008.
Xu, J. Q., J. C. Zhou, S. C. Luo, and S. HePing (2008), Study on characteristics of long-term gravity changes at Wuhan station, Chin. Sci. Bull., 53(13), 2033-2040, doi:10.1007/s11434-008-0074-2.

Zerbini, S., B. Richter, M. Negusini, C. Romagnoli, D. Simon, F. Domenichini, and W. Schwahn (2001), Height and gravity variations by continuous GPS, gravity and environmental parameter observations in the southern Po Plain, near Bologna, Italy, Earth Planet. Sci. Lett., 192, 267-279, doi:10.1016/S0012-821X(01)00445-9.

O. de Viron, Institut de Physique du Globe de Paris, University Paris Diderot, CNRS 7154, 4 Place Jussieu, 75252 Paris Cedex 5, France.

L. Métivier, Institut Géographique National, LAREG (Laboratoire de Recherche en Geodesie), 6-8 Avenue Blaise Pascal, 77455 Marne la Vallée Cedex 2, France.

B. Meurers, Institut für Meteorologie und Geophysik, Universität Wien, Althanstrasse 14, 1090 Wien, Austria.

M. Van Camp, Department of Seismology, Observatoire Royal de Belgique, Avenue Circulaire 3, 1180 Brussels, Belgium. (mvc@oma.be)

S. D. P. Williams, Proudman Oceanographic Laboratory, Bidston Observatory, Joseph Proudman Bldg., 6 Brownlow St., Liverpool, L3 5DA, United Kingdom. 